Research Article

\title{
Analytical Solution of Seepage Field in Karst Tunnel
}

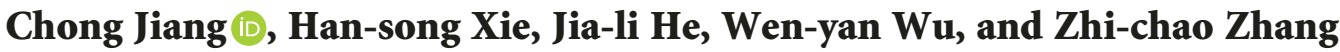 \\ School of Resources and Safety Engineering, Central South University, Changsha 410083, Hunan, China \\ Correspondence should be addressed to Chong Jiang; jiang4107@sohu.com
}

Received 17 May 2018; Revised 15 August 2018; Accepted 27 August 2018; Published 20 September 2018

Academic Editor: Zhongwei Chen

Copyright $\odot 2018$ Chong Jiang et al. This is an open access article distributed under the Creative Commons Attribution License, which permits unrestricted use, distribution, and reproduction in any medium, provided the original work is properly cited.

An analytical solution for the seepage field in water-filled karst tunnel is derived based on the inversion of complex function and groundwater hydraulics theory. The solution considers the distance between the tunnel and the cavern, the size of the cavern, and the properties of the lining structure, such as the permeability coefficient as well as the radius of the grouting ring. This paper also performed numerical simulations for two cases: the application of gravity and the absence of gravity. The numerical solution was obtained to verify the analytical solution, and a good agreement was found. Then, the effect of parameters is discussed in detail, including the distance between the tunnel and the cavern, the radius of the cavern, the grouting ring, and the initial support. The results show that when the radius of the cavern is constant, the pressure head and seepage flow decrease as the distance between the tunnel and the cavern increases. When the distance is constant, the pressure head and seepage flow increase with the increase of the radius of the cavern. In addition, the pressure head and the seepage flow decrease with the increase of the thickness of the grouting ring and decrease with the decrease of the permeability coefficient. As the thickness of the initial support increases, the pressure head gradually increases and the percolation decreases. Furthermore, due to the great influence of the grouting ring and initial support on the pressure head and seepage flow, the thickness and permeability coefficient of the grouting ring and initial support should be taken into account carefully during construction.

\section{Introduction}

In recent years, with the development of the Belt and Road strategy, the construction of tunnels has developed rapidly. And it is possible to build a tunnel in the karst zone in southwestern China. The karst water has a great influence on the construction of the tunnel. Its seepage causes karst tunnel water gushing, and it is easy to cause tunnel deformation and other disasters when the water volume is too large. Therefore, it is important to study the distribution of seepage field in karst tunnels.

The analysis of seepage field in karst tunnels generally uses analytical method and numerical simulation. Based on well mapping theory and superposition principle, Zhang [1] deduced the potential function and distribution of water head in the karst tunnel, but did not study the influence of karst water on tunnel lining structure. Zhang [2] derived the analytical solution of the seepage field of a semiinfinite parallel double-hole tunnel through the seepage mechanics and image method. Yang et al. [3] studied the effect of seismic loading on the double-sided slope of high water content sandy clay. Wu [4] deduced the analytic solution of the complex variable function for the distribution of high water pressure seepage field according to the conformal mapping theory. Park et al. [5] compared two existing analytical solutions for the steady-state groundwater inflow into a drained circular tunnel in a semiinfinite aquifer. Some researchers used the theory of hydraulics and complex functions to solve the analytical solution of seepage field of underwater tunnel composed of surrounding rocks and lining structures [6-9]. Based on the theory of the growth of pore pressure caused by linear waves, Xiong et al. [10] developed an analytical solution of the seepage field of a tunnel affected by the wave in the semiinfinite aquifer. Ma et al. $[11,12]$ carried out some experimental investigations on hydraulic characteristics and seepage characteristics. Lei [13] acquired an analytical solution for steady flow into a tunnel based on the image method. Huangfu et al. [14] studied analytical solutions for steady groundwater flowing into a horizontal tunnel in the semiinfinite aquifer. 
However, most of the aforementioned literature have studied high hydraulic pressure tunnels or high hydraulic parallel tunnels in a semiinfinite plane. There is less analytical formula for the distribution of seepage field in karst tunnels. Therefore, based on the inversion of complex function and groundwater hydraulics theory, this paper deduces the distribution of seepage field in karst tunnels and calculates the amount of seepage. The formula related to pressure head and tunnel seepage is deduced from the relationship between the grouting ring, initial support, and secondary lining. The results are compared with the numerical solutions of the two cases of gravity and no gravity. The change of lining structure characteristics such as grouting circle and initial support is discussed in detail. It is helpful for us to have a deeper understanding of underground water seepage in karst tunnels, and to take effective measures to reduce the harmful effects of karst water on tunnels, so as to provide references for such problems in the future.

\section{Calculation Model}

The schematic diagram of the karst tunnel in an infinite plane is shown in Figure 1. Here, $q$ is the water pressure in the karst cavern, $a$ is the tunnel radius, and $d$ is the distance between the center of the tunnel and the karst cavern. Additionally, the basic assumptions are as follows:

(1) The surrounding rock of the tunnel is homogeneous with isotropic permeability [5]

(2) The aquifer and karst water are incompressible. The flow is in a steady state and is governed by Darcy's law [13]

(3) Due to the long distance from the tunnel to the surface, it is assumed that the plane where the karst tunnel is located is an infinite plane, and the seepage field is only affected by karst water

(4) When studying the lining structure, the pore pressure is constant on the same ring, and the waterfilling hole is equal to the water pressure head [7]

\section{Analytical Solution of Seepage Field}

3.1. Analytical Method. Considering the characteristics of karst tunnels, the inversion of complex functions and groundwater hydraulics is used to analyze the seepage field of karst tunnels. The solution steps are as follows:

(a) According to the complex potential function of the point source and the inverse transformation relation, the mirror image points $a^{2} / \overline{z_{0}}$ of $z_{0}$ in the tunnel are obtained, and the complex potential function at any place in the seepage plane of the karst tunnel is solved

(b) Through the resetting potential at any place in the seepage plane of the karst tunnel, the potential function, flow function, and complex velocity of the seepage field in the karst tunnel are solved

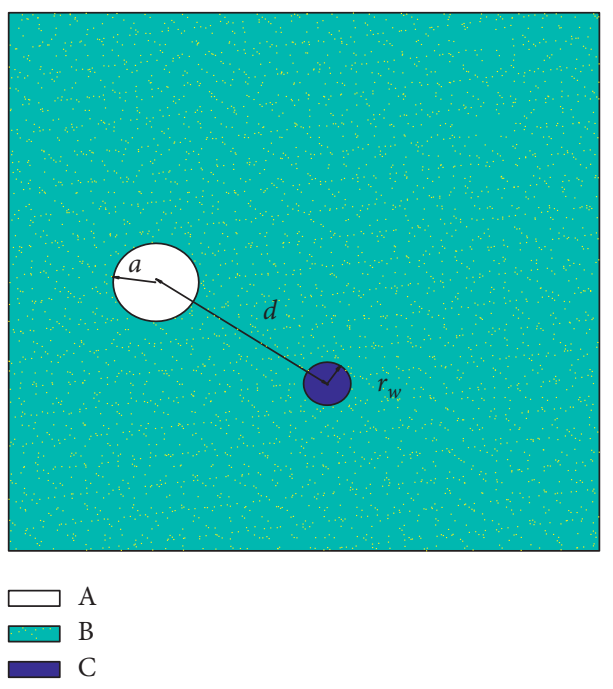

FIgURE 1: Schematic diagram of karst tunnel in infinite plane. A: tunnel; B: surrounding rocks; C: cavern.

(c) The seepage flow and pressure head are obtained by the boundary conditions, and the head pressure and the seepage flow in each lining structure were solved according to the relationship of the lining structures

3.2. Analysis of Complex Potential Function. The water-filled cavern existing outside the tunnel is treated as a constant point source, and the inversion of the cavern and tunnel is shown in Figure 2. In the infinite plane where the tunnel radius is $a$, there is a cavern with the water pressure $q$ at $z_{0}=x_{0}+i y_{0}$ outside the tunnel. The cavern is considered as a point source. After the inversion transformation, a cavern with the same intensity is generated at $a^{2} / \overline{z_{0}}$, which is calculated as a point sink. The complex potential function of the point $z=x+i y$ in the infinite plane of the point source $z_{0}=x_{0}+i y_{0}$ is

$$
f(z)=\frac{q}{2 \pi} \ln z=\frac{q}{2 \pi} \ln \left(a e^{i \theta}\right),
$$

where the potential function is $\phi=q / 2 \pi \ln a$ and the flow function is $\varphi=q / 2 \pi \theta$.

Based on the complex potential function of the point source in the infinite plane and the inversion transformation relationship, the conjugate complex potential function of the point sink is obtained:

$$
\bar{f}\left(\frac{a^{2}}{z}\right)=-\frac{q}{2 \pi} \ln z\left(-\frac{a^{2}}{z_{0}}\right) .
$$

The point source in the unbounded fluid has a reset potential of $f(z)$, and the conjugate reset potential of the point converted according to the inversion is $\bar{f}\left(a^{2} / \mathrm{z}\right)$. All the points are in the region of $|z|>a$ outside the tunnel. In the flow field behind the tunnel $|z|=a$, the tunnel wall can be a resetting potential of a streamline. According to the superposition principle of resetting potential in seepage mechanics, the complex potential function of the point seeping in the infinite plane of the tunnel is obtained: 


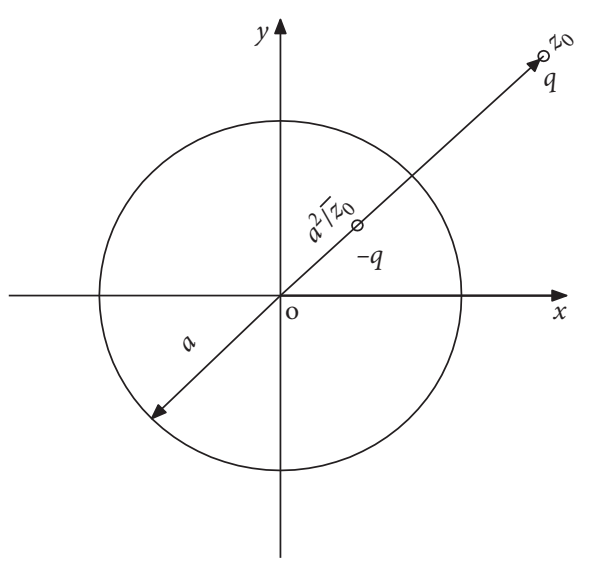

FIgURE 2: Schematic diagram of inversion of caverns and karst tunnels.

$$
F(z)=f(z)+\bar{f}\left(\frac{a^{2}}{z}\right)
$$

3.3. Analysis of Seepage Field. According to the complex potential formula (3) of the point in the infinite plane of the tunnel, formulas (1) and (2) are plugged into (3), as shown in the following:

$$
F(z)=\frac{q}{2 \pi} \ln \left(z-z_{0}\right)-\frac{q}{2 \pi} \ln \left(z-\frac{a^{2}}{\overline{z_{0}}}\right) .
$$

For simplicity, without loss of generality, the point source can be selected to the right of the horizontal direction of the tunnel; that is, the $x$-axis passes through the point source. Then, there is $z_{0}=\overline{z_{0}}=x_{0} \equiv d$, as shown in Figure 3 . Therefore, Formula (4) can be written as

$$
\begin{aligned}
F(z)= & \frac{q}{2 \pi} \ln (z-d)-\frac{q}{2 \pi} \ln \left(z-\frac{a^{2}}{d}\right), \\
= & \frac{q}{2 \pi} \ln \sqrt{(x-d)^{2}+y^{2}}-i \frac{q}{2 \pi} \operatorname{arctg} \frac{y}{x-d} \\
& -\frac{q}{2 \pi} \ln \sqrt{\left(x-\frac{a^{2}}{d}\right)^{2}+y^{2}}+i \frac{q}{2 \pi} \operatorname{arctg} \frac{y}{x-\left(a^{2} / d\right)} .
\end{aligned}
$$

Complex velocity:

$$
\begin{aligned}
W(z) & =\frac{d F}{d z}=\frac{(q / 2 \pi) \ln (z-d)-(q / 2 \pi) \ln \left(z-\left(a^{2} / d\right)\right)}{d z}, \\
& =\frac{q}{2 \pi}\left(\frac{1}{z-d}-\frac{1}{z-\left(a^{2} / d\right)}\right)
\end{aligned}
$$

The potential function of the point source in the infinite plane of the tunnel:

$$
\phi=\frac{q}{4 \pi} \ln \frac{(x-d)^{2}+y^{2}}{\left(x-\left(a^{2} / d\right)\right)^{2}+y^{2}} .
$$

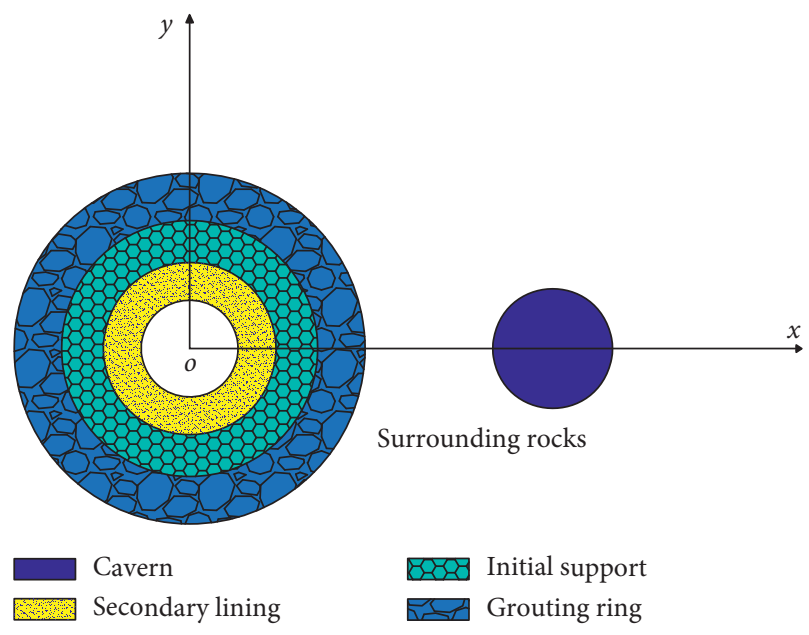

FIgURE 3: Schematic diagram of the relationship between each lining structure.

The flow function of the point source in the infinite plane of the tunnel:

$$
\varphi=-\frac{q}{2 \pi} \operatorname{arctg} \frac{y}{x-d}+\frac{q}{2 \pi} \operatorname{arctg} \frac{y}{x-\left(a^{2} / d\right)} .
$$

Boundary conditions:

Cavern boundary:

$$
\Phi_{w}=-\frac{q}{2 \pi} \ln \frac{r_{w}}{l} .
$$

Tunnel boundary:

$$
\Phi_{s}=-\frac{q}{2 \pi} \ln \frac{d}{a}
$$

where $l$ is the distance between the mirror point $a^{2} / \overline{z_{0}}$ and $z_{0}, r_{w}$ is the radius of the cavern, $\Phi_{w}$ is the cavern potential function, and $\Phi_{s}$ is the tunnel potential function.

According to the boundary conditions and the steadystate percolation of the single-phase liquid [15], it can be obtained that

$$
\begin{aligned}
q & =\frac{2 \pi\left(\Phi_{w}-\Phi_{s}\right)}{-\ln \left(a r_{w} / l d\right)}=\frac{2 \pi\left(\Phi_{w}-\Phi_{s}\right)}{\ln \left(d^{2}-a^{2} / a r_{w}\right)}, \\
H_{w} & =\frac{p_{w}}{\rho g}, H_{s}=\frac{p_{s}}{\rho g}, \\
Q & =\frac{2 \pi K \rho g\left(H_{w}-H_{s}\right)}{\ln \left(d^{2}-a^{2} / a r_{w}\right)},
\end{aligned}
$$

where $K$ is the permeability, $P_{w}$ and $P_{s}$ are the head pressures of the cavern and tunnel, respectively, $Q$ is the unit permeate flow, $H_{w}$ is the head pressure of the cavern, and $H_{s}$ is the head pressure of the tunnel boundary, that is, the head pressure of the surface of the grouting ring.

3.4. Analysis of Seepage Field of Lining Structure. The seepage field in the lining and grouting circle cannot be solved by the complex function, but it can be solved by using the groundwater seepage mechanics and the shaft theory [6]. 
The relationship between the initial support, the secondary lining, and the grouting ring pressure head is shown in Figure 3, and the formulas are as follows:

$$
\begin{aligned}
& H_{s}-H_{1}=\frac{Q}{2 \pi k_{1}} \ln \frac{a}{r_{1}}, \\
& H_{1}-H_{2}=\frac{Q}{2 \pi k_{2}} \ln \frac{r_{1}}{r_{2}}, \\
& H_{2}-H_{3}=\frac{Q}{2 \pi k_{3}} \ln \frac{r_{2}}{r_{3}},
\end{aligned}
$$

$$
Q=\frac{2 \pi\left(H_{w}-H_{3}\right)}{\left(1 / k_{2}\right) \ln \left(r_{1} / r_{2}\right)+\left(1 / k_{1}\right) \ln \left(a / r_{1}\right)+\left(1 / k_{3}\right) \ln \left(r_{2} / r_{3}\right)+(1 / k) \ln \left(d^{2}-a^{2} / a r_{w}\right)}
$$

Head pressure of initial support and secondary lining joint:

$$
H_{2}=H_{3}+\frac{\left(H_{w}-H_{3}\right)}{k_{3} A} \ln \frac{r_{2}}{r_{3}}
$$

Head pressure of grouting circle and initial support connection:

$$
H_{1}=H_{3}+\frac{\left(H_{w}-H_{3}\right)}{k_{3} A} \ln \frac{r_{2}}{r_{3}}+\frac{\left(H_{w}-H_{3}\right)}{k_{2} A} \ln \frac{r_{1}}{r_{2}} .
$$

In the formula,

$$
A=\frac{1}{k_{2}} \ln \left(\frac{r_{1}}{r_{2}}\right)+\frac{1}{k_{1}} \ln \left(\frac{a}{r_{1}}\right)+\frac{1}{k_{3}} \ln \left(\frac{r_{2}}{r_{3}}\right)+\frac{1}{k} \ln \left(\frac{d^{2}-a^{2}}{a r_{w}}\right) \text {, }
$$

where $k$ is the permeability coefficients of the surrounding rock.

According to different stages of construction such as tunnel holes and grouting, the different water pressure distribution can be obtained. When tunnel grouting and initial support are completed, the tunnel seepage is

$$
Q=\frac{2 \pi\left(H_{w}-H_{2}\right)}{\left(1 / k_{2}\right) \ln \left(r_{1} / r_{2}\right)+\left(1 / k_{1}\right) \ln \left(r / r_{1}\right)+(1 / k) \ln \left(d^{2}-a^{2} / a r_{w}\right)} \text {. }
$$

Head pressure of grouting circle and initial support connection:

$$
H_{1}=H_{2}+\frac{\left(H_{w}-H_{2}\right) \ln \left(r_{1} / r_{2}\right)}{\ln \left(r_{1} / r_{2}\right)+\left(k_{2} / k_{1}\right) \ln \left(r / r_{1}\right)+\left(k_{2} / k\right) \ln \left(d^{2}-a^{2} / a r_{w}\right)} .
$$

\section{Verification and Discussion}

4.1. Numerical Verification. Based on the complex function and groundwater hydraulics theory, the distribution of seepage field suitable for homogeneous and isotropic karst tunnels and lining structures were deduced. In order to where $H_{s}$ is the head pressure of the surface of the grouting ring; $H_{1}, H_{2}$, and $H_{3}$ are the head pressures of the joints of the grouting ring and the initial support, the initial support and the secondary lining joint, and the secondary lining inner surface, respectively; $r_{1}, r_{2}$, and $r_{3}$ are the radius of the grouting ring, initial support, and internal of secondary lining, respectively; $k_{1}, k_{2}$, and $k_{3}$ are the permeability coefficients of the grouting circle, initial support, and secondary lining, respectively.

Because of the same seepage, the above equations can be integrated to obtain the tunnel seepage when the grouting circle, the initial support, and the two lining are completed: ensure the accuracy of the analytical solution of the karst tunnel, the numerical solution simulated by the finite difference software FLAC ${ }^{3 \mathrm{D}}$ is compared with the theoretical solution obtained by the method used in this paper.

The calculation conditions are listed as follows: the head pressure of the cavern is $54 \mathrm{~m}$; the radius of the cavern is $4 \mathrm{~m}$; the radius of the tunnel is $7.25 \mathrm{~m}$; the radius of the grouting circle is $2.25 \mathrm{~m}$; and the initial support radius is $0.25 \mathrm{~m}$; the permeability coefficient of surrounding rocks is $1.5 \times 10^{-6} \mathrm{~cm} \cdot \mathrm{s}^{-1}$; the permeability coefficient of grouting ring is $10^{-7} \mathrm{~cm} \cdot \mathrm{s}^{-1}$; the initial support permeability coefficient of initial support is $10^{-8} \mathrm{~cm} \cdot \mathrm{s}^{-1}$.

Six groups of $100 \mathrm{~m} \times 100 \mathrm{~m}$ models of caverns on the right side of the tunnel were established and calculated with FLAC $^{3 \mathrm{D}}$. The pore water pressure of the tunnel with gravity and without gravity was obtained, respectively. The six groups of models are $d=15 \mathrm{~m}, d=20 \mathrm{~m}, d=25 \mathrm{~m}$, $d=30 \mathrm{~m}, d=35 \mathrm{~m}$, and $d=40 \mathrm{~m}$. When $d=20 \mathrm{~m}$, the karst tunnel model consists of 4236 elements, as shown in Figure 4. Figures 5 and 6 are contours of zone pore pressure with gravity and without gravity, respectively.

The pore water pressures extracted from the six groups of numerical simulation data in Figure 5 with gravity and Figure 6 without gravity are compared with the theoretical solutions. The results are shown in Figure 7. The law obtained by numerical and theoretical solutions is that when the grouting ring and the initial support are completed and the secondary lining is not yet completed, $H_{1}$ decreases with the increase of $d$. Moreover, the curves have a good consistency. When $d=15 \mathrm{~m}$, the analytical solution for $H_{1}$ is $25.78 \mathrm{~m}$, the numerical solution with gravity is $25.67 \mathrm{~m}$, and the numerical solution without gravity is $25.77 \mathrm{~m}$. Therefore, the analytical method in this paper is suitable for solving the distribution of seepage field in karst tunnels.

4.2. The Effect of Distance and Cavern Radius. Figure 8 shows the relationship between $H_{1}$ and $d$. Figure 9 shows the relationship between $Q$ and $r_{w}$. In the infinite plane, when $H_{s}$ is constant, the main factors affecting $H_{1}$ and $Q$ in the 


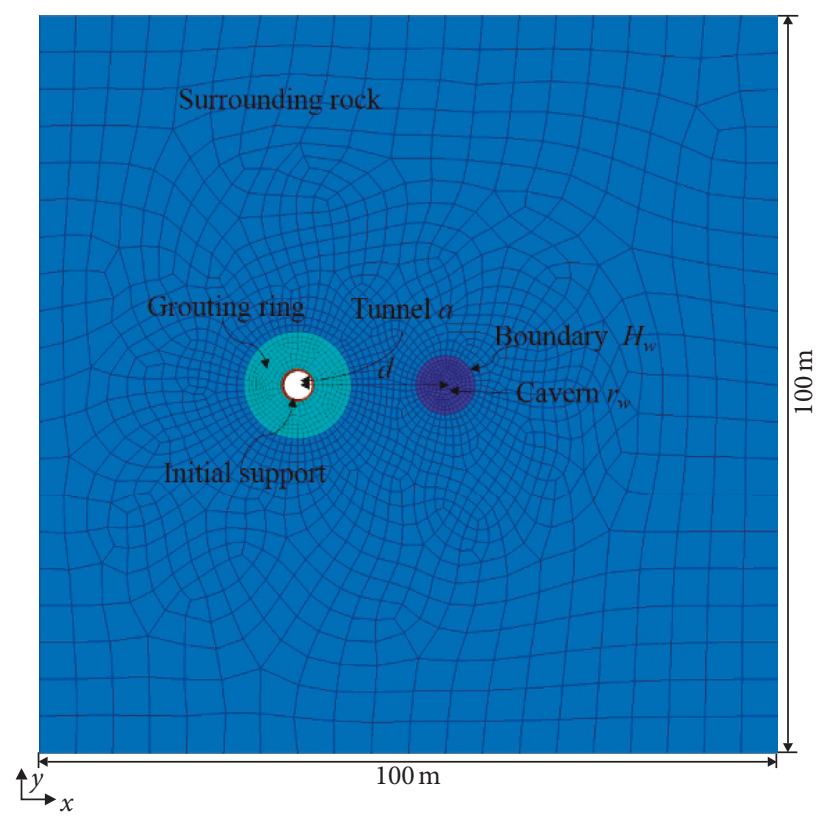

FIgURE 4: Finite element model with circular karst tunnel.

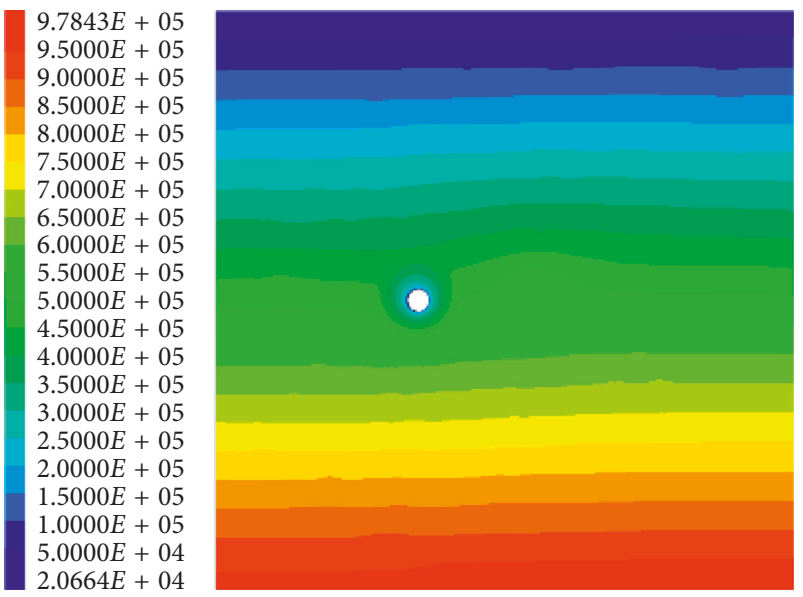

FIGURE 5: Contour of pore water pressure with gravity for $d=20$, $a=7.25$, and $r_{w}=4$.

tunnel are $r_{w}$ and $\mathrm{d}$. When $r_{w}$ is constant, $H_{1}$ and $Q$ decrease with the increase of $d$. When $d$ is constant, $H_{1}$ and $Q$ gradually increase as $r_{w}$ increases.

4.3. The Effect of Grouting Ring. When the diameter of the grouting ring and the initial support radius is constant, the tunnel radius and the thickness of the grouting ring increase. Figures 10-13 show that $H_{1}$ and $Q$ gradually decrease with the increase of the thickness of the grouting ring when the ratio between the distance and the permeability coefficient is constant. When the thickness of the grouting ring was $0.25 \mathrm{~m}$ and $a$ reached $6 \mathrm{~m}, \mathrm{Q}$ and $H_{1}$ decreased to $41.94 \%$ and $41.86 \%$, respectively. When $a$ is constant, $H_{1}$ and $Q$ gradually decrease as the permeability coefficient decreases. When $a$ increases to $7 \mathrm{~m}$, the rate of $H_{1}$ and $Q$ decrease gradually. From Figures 12 and 13, when $a$ is constant, $H_{1}$

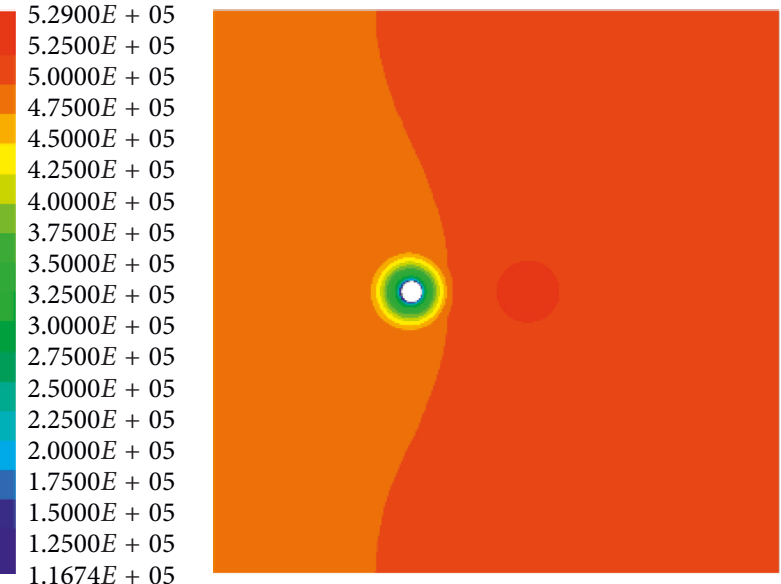

FIGURE 6: Contour of pore water pressure without gravity for $d=20, a=7.25$, and $r_{w}=4$.

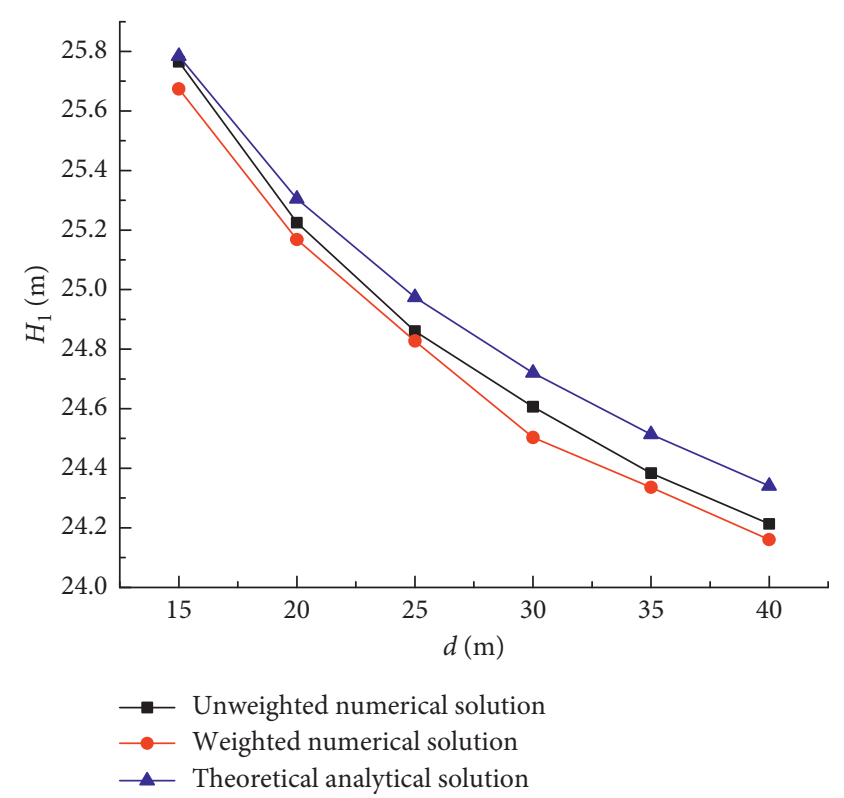

Figure 7: Comparison of numerical solution and theoretical solution for $a=7.25$ and $r_{w}=4$.

becomes smaller as the seepage coefficient of the grouting ring decreases. When $k_{r}=k / k_{1}$ increases to $80, Q$ decreases to $22.4 \%$ of $Q$ when $k_{r}=5$, and the $Q$ reduction rate gradually decreases. In summary, increasing the thickness of the grouting ring and reducing the permeability coefficient of the grouting ring can reduce $Q$ and $H_{1}$. However, excessively increasing the thickness of the grouting ring will not only increase the cost but also reduce the impact on the pressure head and seepage flow. Therefore, a reasonable grouting material and construction process should be selected to ensure the thickness of the grouting ring when the permeability coefficient of the grouting ring is less than the specified value.

4.4. The Effect of Initial Support. When the inner diameter $r_{1}$ of the grouting ring is constant, increasing $r_{2}$ is to reduce the 


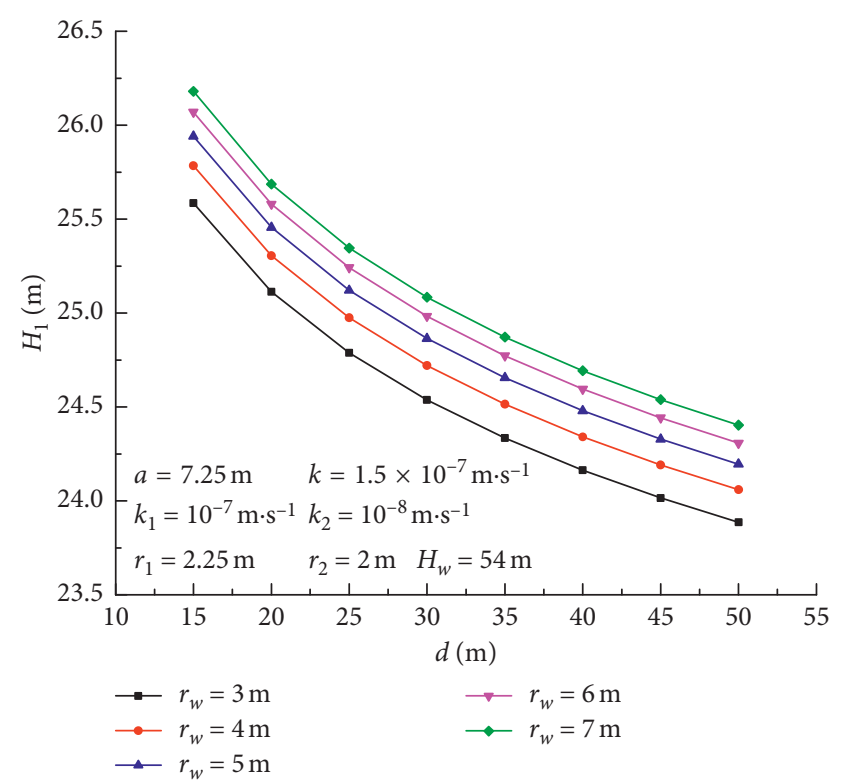

Figure 8: Relationship between head pressure and distance.

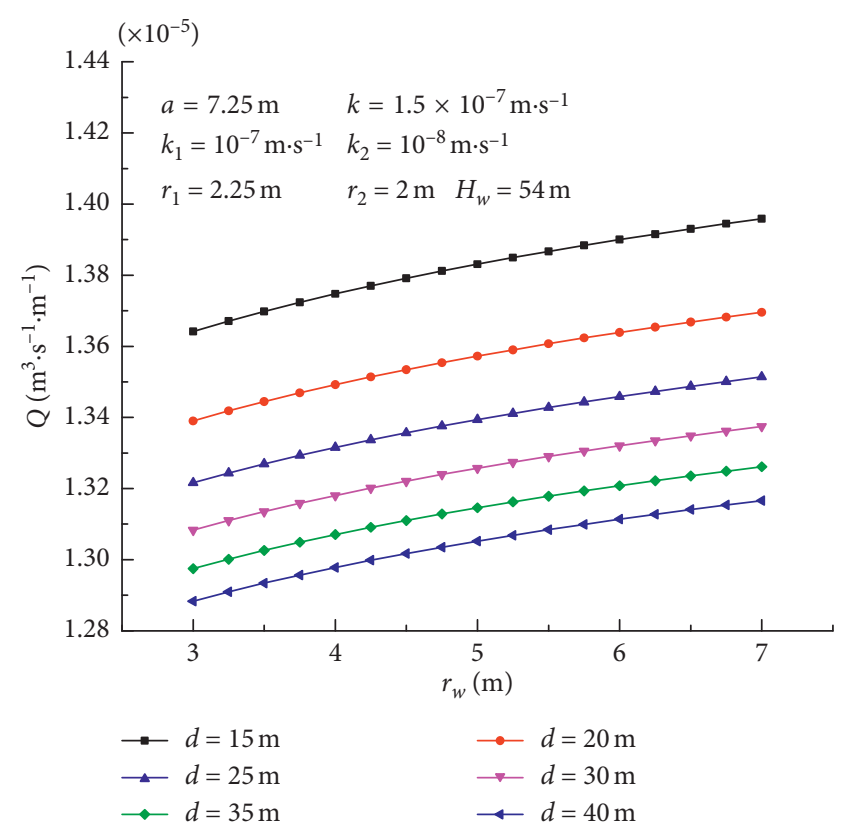

FIgURE 9: Relationship between seepage flow and cavern radius.

thickness of the initial support. Figures 14 and 15 show that as the thickness of the initial support decreases, $H_{1}$ decreases and $Q$ increases gradually. When $r_{2}=2.25 \mathrm{~m}, Q$ and $H_{1}$ are $13.3 \%$ of $Q$ and $207 \%$ of $H_{1}$ when $r_{2}=4.75 \mathrm{~m}$, respectively. It shows that the initial support thickness has a great influence on the pressure head. During construction, we should pay attention to the safety range of the initial support thickness.

If the initial diameter $r_{2}$ and $a$ are constant, increasing $r_{1}$ means increasing the thickness of the initial support and reducing the thickness of the grouting ring. In Figures 16

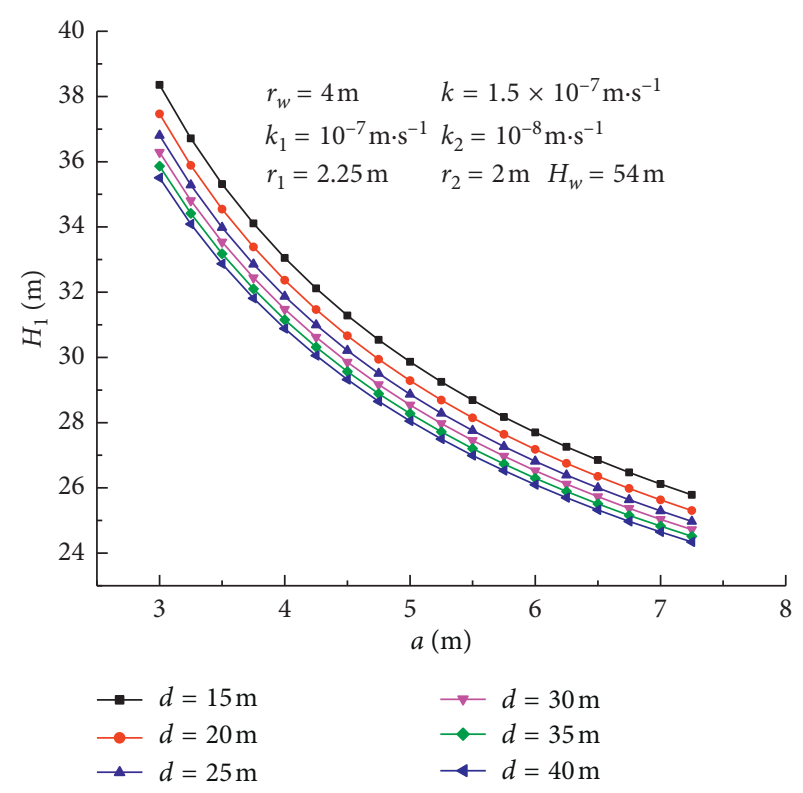

FIGURE 10: Effect of $d$ on the relationship between pressure head and tunnel radius.

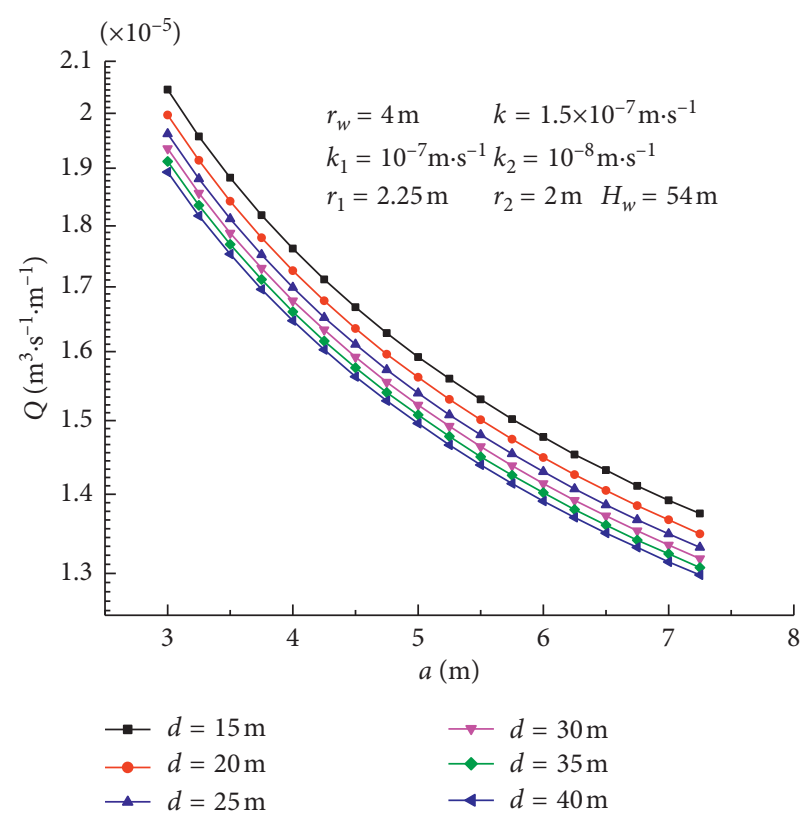

FIGURE 11: Relationship between seepage flow and tunnel radius.

and 17 , with the increase of $r_{1}, H_{1}$ gradually increases and $Q$ gradually decreases.

As shown in Figures 18 and 19, the permeability coefficient of grouting ring is constant, and $H_{1}$ gradually decreases and $Q$ gradually increases with the increase of $k_{2}$. The change rate of $Q$ and $H_{1}$ is larger when $k_{2}<10^{-8} \mathrm{~cm} \cdot \mathrm{s}^{-1}$. When $k_{2}=2 \times 10^{-8} \mathrm{~cm} \cdot \mathrm{s}^{-1}$, both $Q$ and $H_{1}$ tend to be stable. When the other conditions are constant, the change of $k_{2}$ on the magnitude of $10^{-8}$ has little effect on $Q$ and $H_{1}$, but the influence on the magnitude of $10^{-9}$ is greater. 


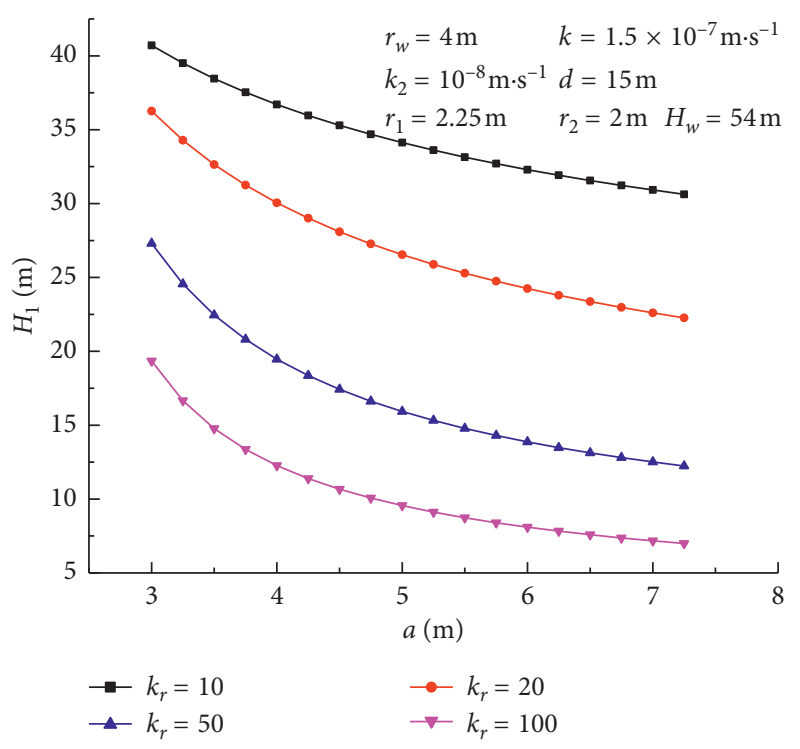

FIGURE 12: Effect of $k_{r}$ on the relationship between pressure head and tunnel radius.

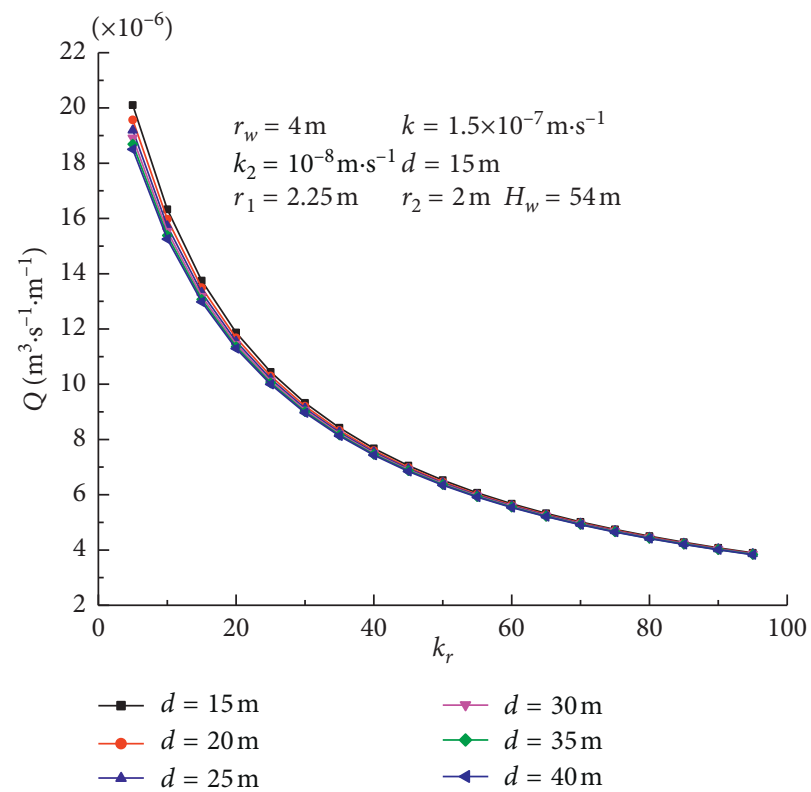

FIGURE 13: Relationship between seepage flow and permeability coefficient.

\section{Conclusion}

Based on the inversion of complex function and groundwater hydraulics theory, this paper derives the analytical solution for the karst seepage field in the karst tunnel in an infinite plane. The potential function, the flow function, and the complex velocity at any place in the infinite plane are solved. According to the distribution of the seepage field and the boundary conditions, the seepage flow of the karst tunnel is obtained. The seepage field of the lining structure is deduced from the relationship between the grouting ring, the initial support, and the secondary lining. The new solution

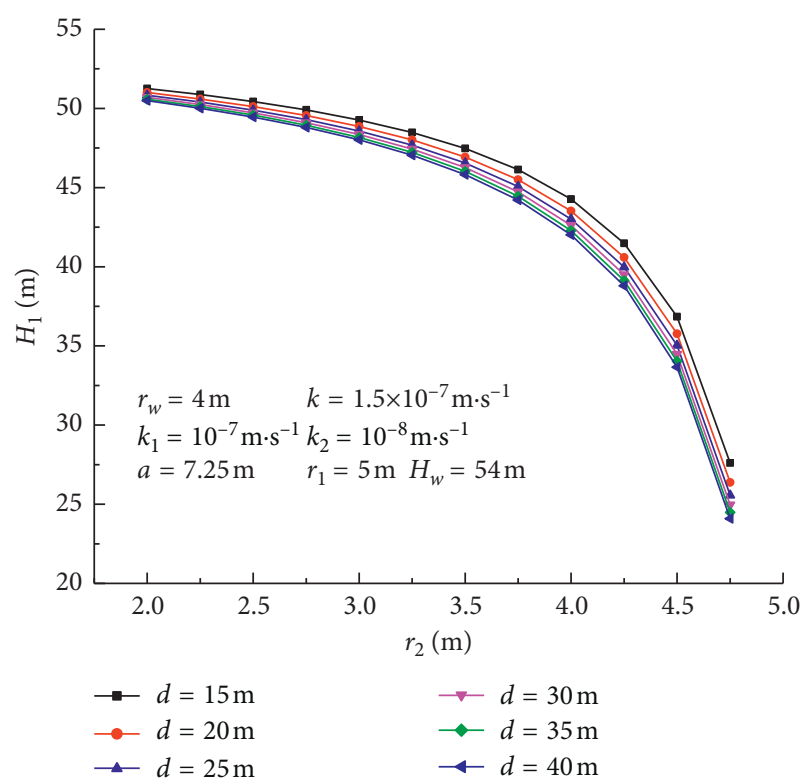

FIGURE 14: Relationship between pressure head and initial support radius.

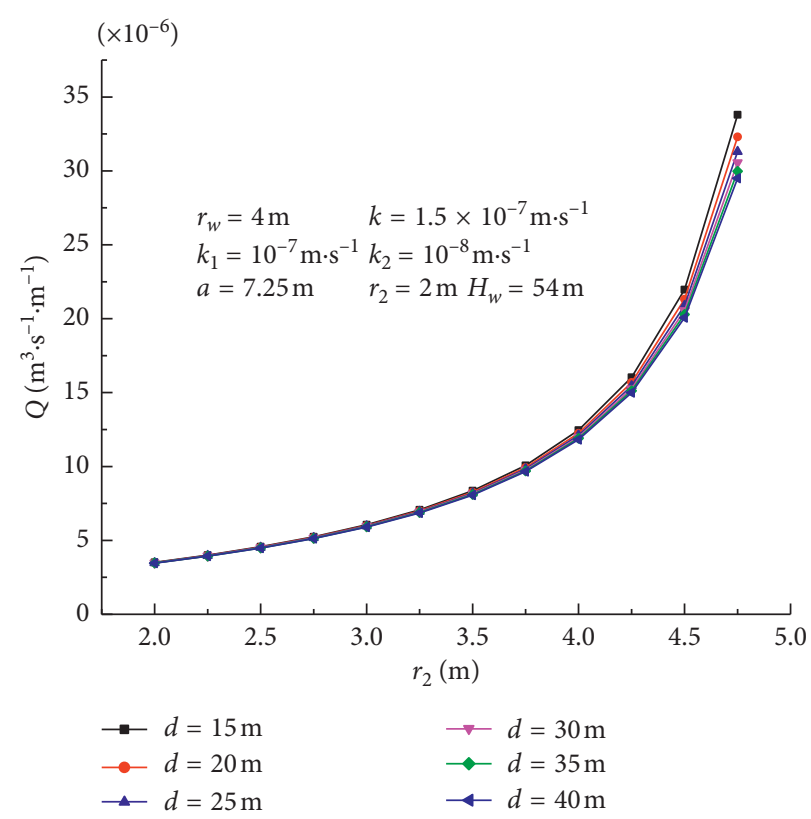

FIGURE 15: Relationship between seepage flow and initial support radius.

was verified with numerical simulation via the software FLAC $^{3 \mathrm{D}}$. The conclusions obtained from this study are summarized as follows:

(1) When $H_{s}$ is constant for karst tunnels, $r_{w}$ and $d$ are the main factors affecting the pressure head and seepage flow of the tunnel. When $r_{w}$ is constant, $H_{1}$ and $Q$ decrease with the increase of $d$. When $d$ is constant, $H_{1}$ and $Q$ increase with the increase of $r_{w}$.

(2) When the initial support is completed and the secondary lining has not been constructed yet, $H_{1}$ 


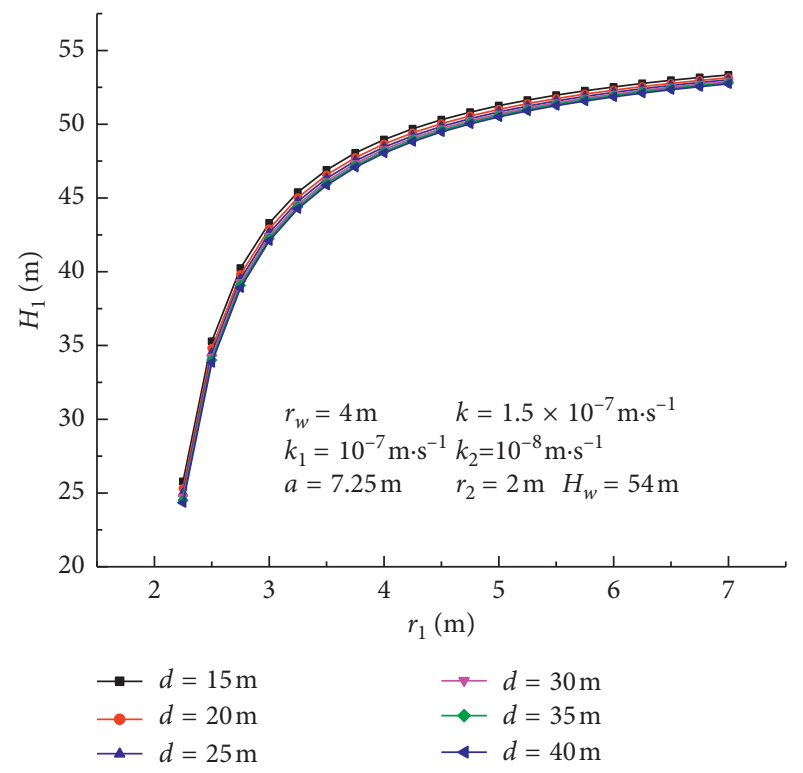

FIGURE 16: Relationship between pressure head and radius of grouting ring.

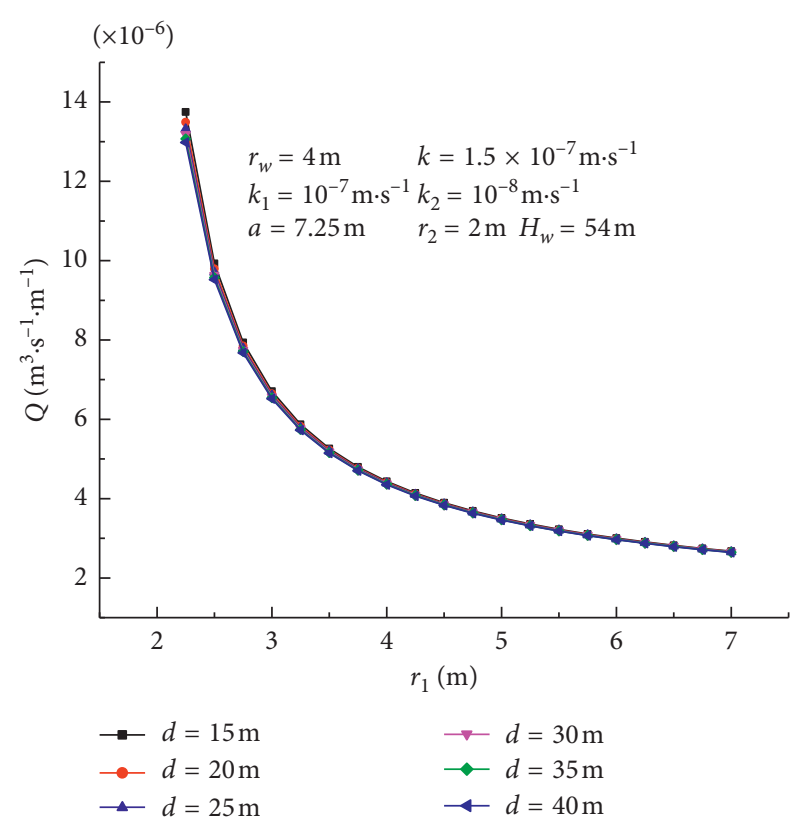

FIgURE 17: Relationship between seepage flow and radius of grouting ring.

and $Q$ will gradually decrease with the increase of the thickness and the decrease of the permeability coefficient of the grouting ring. When the permeability coefficient of grouting ring is less than the specified value, reasonable grouting material and construction technology should be selected to ensure the thickness of grouting ring.

(3) $H_{1}$ gradually decreases with the decrease of the thickness and the increase of $k_{2}$. However, $Q$ gradually increases with the decrease of the thickness and the increase of $k_{2}$. During construction, we

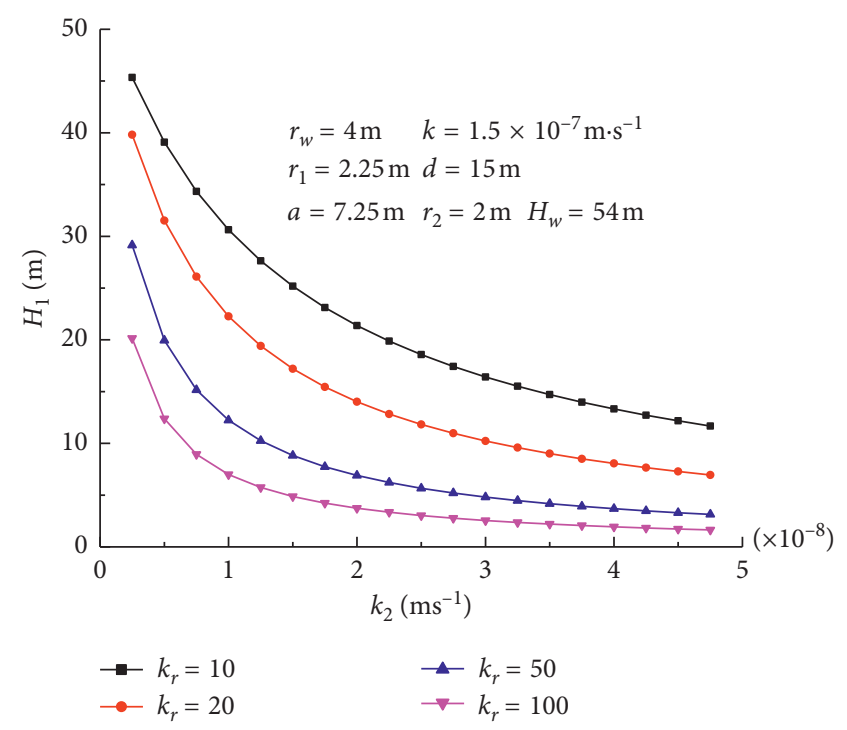

FIGURE 18: Relationship between pressure head and permeability coefficient of grouting ring.

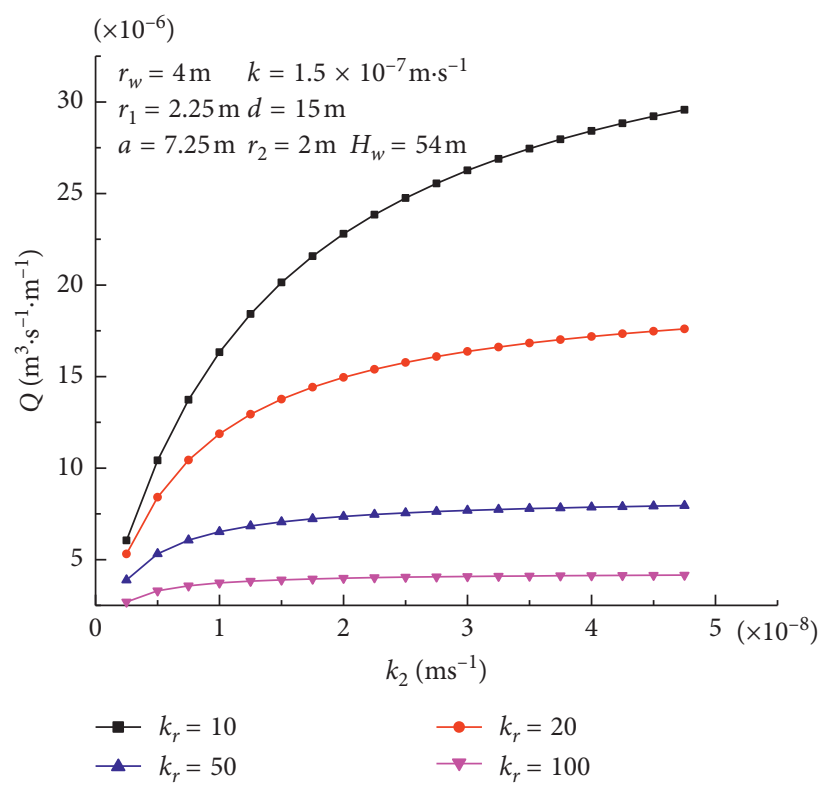

FIgURE 19: Relationship between seepage flow and permeability coefficient of grouting ring.

should pay attention to the safety range of the initial support thickness.

\section{Data Availability}

Based on the "history" function of FLAC3D software, the data which recorded the pore water pressure during the stable period of the monitoring point were obtained. According to the simulation conditions in Chapter 4, readers can complete the modeling process and obtain the contour of pore water pressure such as Figures 5 and 6. The data of the pore water pressure in the stable period of the monitoring point were compared with the analytical solution to 
verify the accuracy. The author only recorded data of the corresponding monitoring point in corresponding area for research needs. In addition, all the sharing data were involved in this paper, and there were no redundant data. The parameters of the lining structure in the numerical simulation conditions come from [6].

\section{Conflicts of Interest}

The authors declare that there are no conflicts of interest regarding the publication of this paper.

\section{Acknowledgments}

This work was supported by the National Natural Science Foundation of China (Grant nos. 51478479 and 51678570) and Hunan Transport Technology Project (Grant no. 201524).

\section{References}

[1] M. D. Zhang, Study on the Characteristics of Seepage Field and Water Pressure on Tunnel Lining in Karst Ground, Beijing Jiaotong University, Beijing, China, 2008.

[2] B. Q. Zhang, "Analytical solution for seepage field of twinparallel tunnel in semi-infinite plane," Journal of The China Railway Society, vol. 39, no. 1, pp. 125-131, 2017.

[3] B. Yang, F. Gao, and D. Jeng, "Failure mode and dynamic response of a double-sided slope with high water content of soil," Journal of Mountain Science, vol. 15, no. 4, pp. 859-870, 2018.

[4] J. G. Wu, A Coupled Fluid-Mechanical Study on Seepage Field of Tunnels with High Hydraulic Pressure, Beijing Jiaotong University, Beijing, China, 2006.

[5] K. H. Park, A. Owatsiriwong, and J. G. Lee, "Analytical solution for steady-state groundwater inflow into a drained circular tunnel in a semi-infinite aquifer: A revisit," Tunnelling and Underground Space Technology, vol. 23, no. 2, pp. 206209, 2008.

[6] C. W. Du, M. S. Wang, Z. S. Tan et al., "Analytic solution for seepage field of subsea tunnel and its application," Chinese Journal of Rock Mechanics and Engineering, no. s2, pp. 3567-3573, 2011.

[7] H. W. Ying, C. W. Zhu, H. W. Shen, and X. N. Gong, "Semianalytical solution for groundwater ingress into lined tunnel," Tunnelling and Underground Space Technology, vol. 76, pp. 43-47, 2018.

[8] L. Tong, K. Xie, M. Lu et al., "Analytical study of seepage flow into a lined tunnel in a semi-infinite aquifer," Rock and Soil Mechanics, vol. 32, no. 1, pp. 304-308, 2011.

[9] D. Ma, Z. Zhou, J. Wu, Q. Li, and H. Bai, "Grain size distribution effect on the hydraulic properties of disintegrated coal mixtures," Energies, vol. 10, no. 5, p. 612, 2017.

[10] H. Xiong, K. Zhao, G. Chen et al., "Analysis of seepage field of underwater tunnel in a semi-infinite aquifer under wave action," China Earthquake Engineering Journal, vol. 36, no. 4, pp. 919-923, 2014.

[11] D. Ma, Q. Li, M. Hall, and Y. Wu, "Experimental investigation of stress rate and grain size on gas seepage characteristics of granular coal," Energies, vol. 10, no. 4, p. 527, 2017.

[12] D. Ma, X. Cai, Z. Zhou, and X. Li, "Experimental investigation on hydraulic properties of granular sandstone and mudstone mixtures," Geofluids, vol. 2018, Article ID 9216578, 13 pages, 2018.

[13] S. Lei, "An analytical solution for steady flow into a Ttonnel," Ground Water, vol. 37, no. 1, pp. 23-26, 1999.

[14] M. Huangfu, M. S. Wang, Z. S. Tan, and X. Y. Wang, “Analytical solutions for steady seepage into an underwater circular tunnel," Tunnelling and Underground Space Technology, vol. 25, no. 4, pp. 391-396, 2010.

[15] Y. Kong, Higher Fluid Mechanics, University of Science and Technology of China Press, Hefei, China, 2010. 


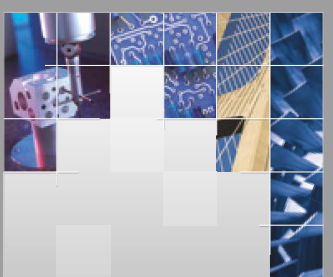

\section{Enfincering}
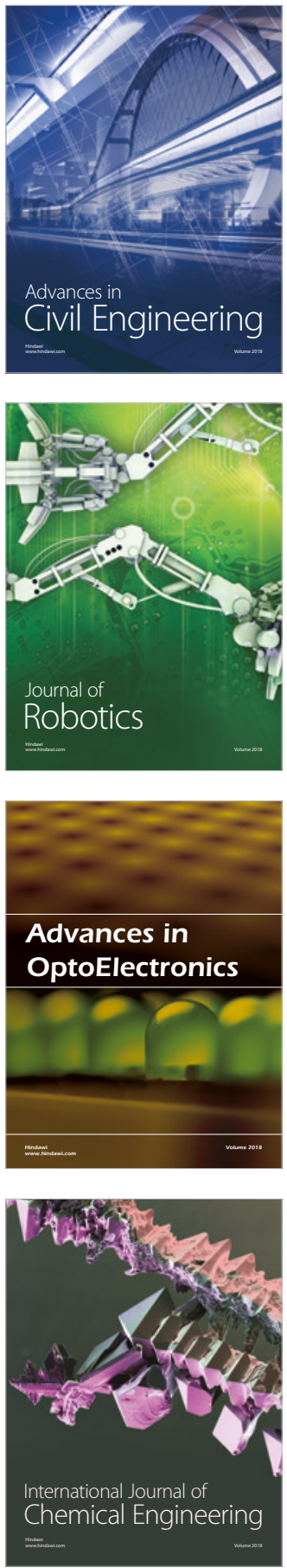

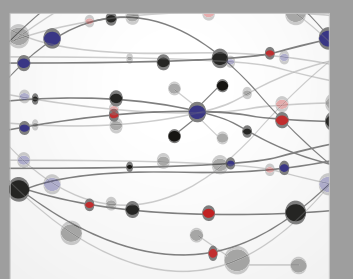

\section{Rotating \\ Machinery}

The Scientific World Journal

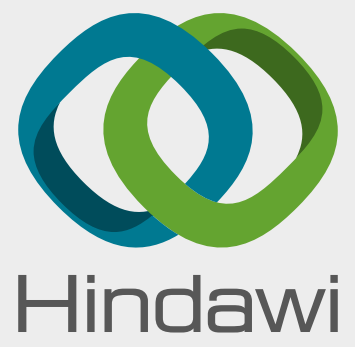

Submit your manuscripts at

www.hindawi.com
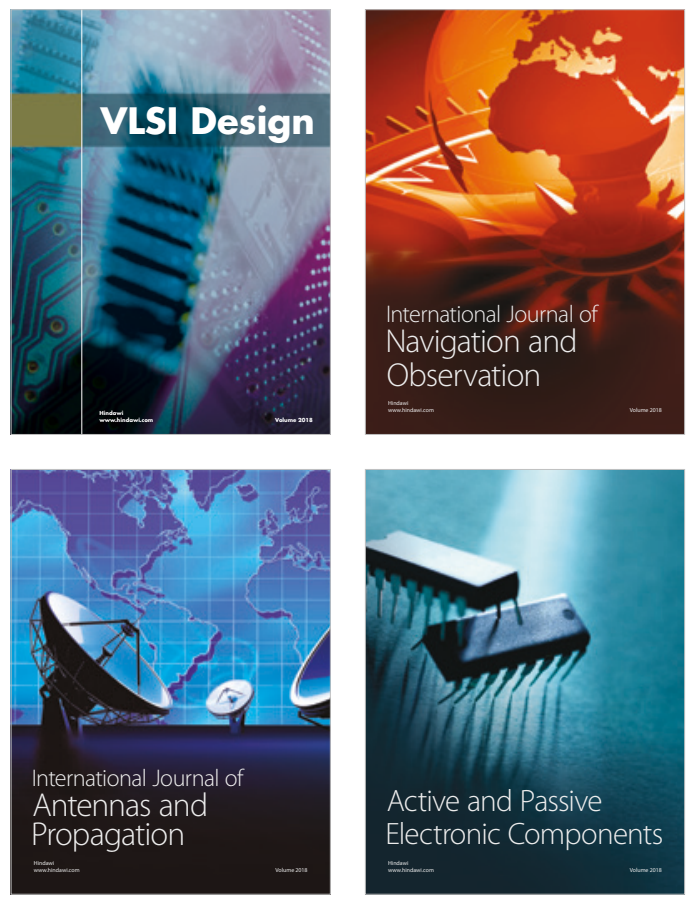
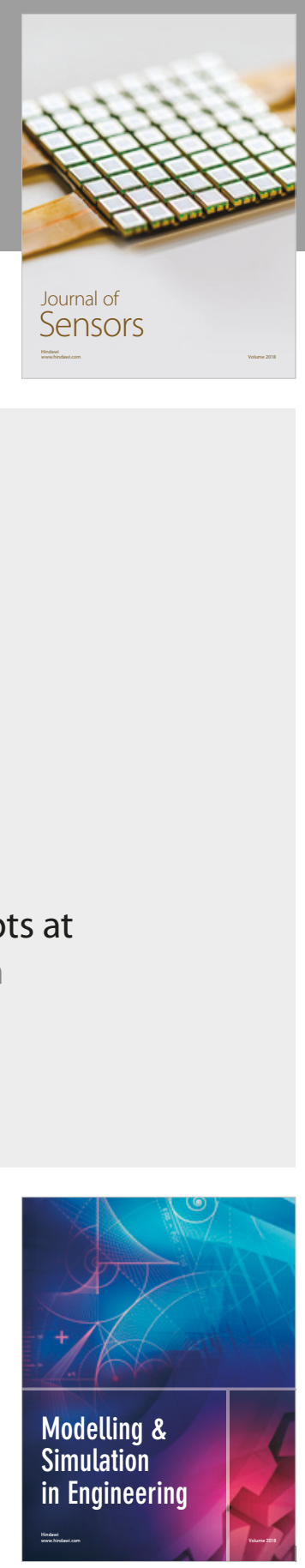

\section{Advances \\ Multimedia}
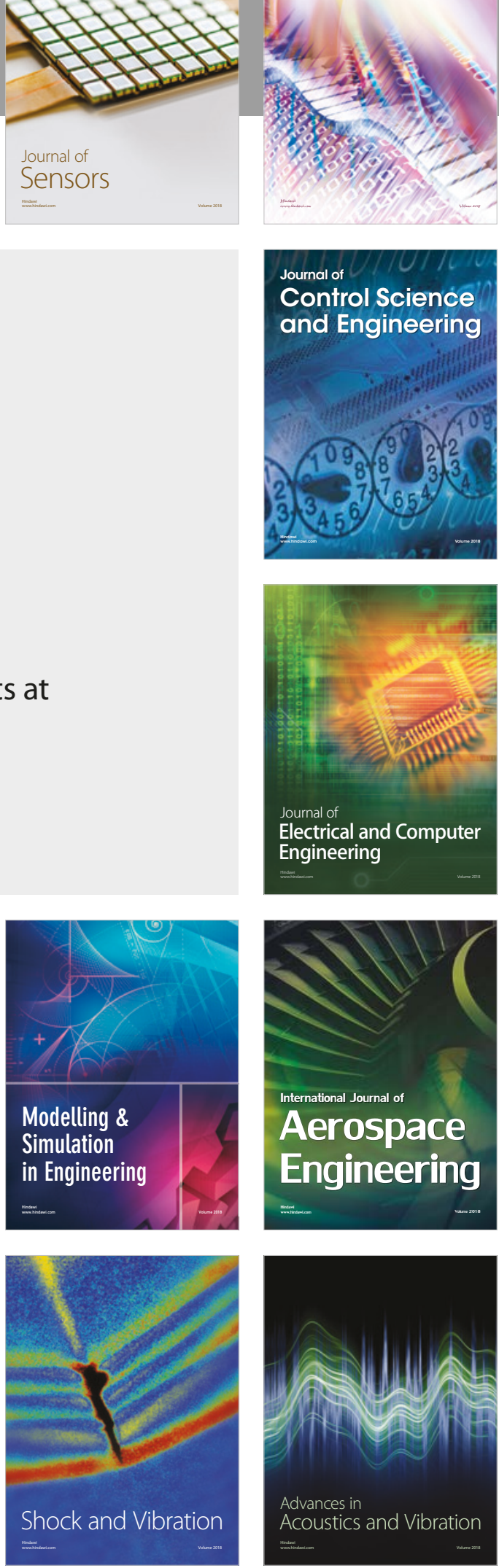